This item was submitted to Loughborough's Research Repository by the author.

Items in Figshare are protected by copyright, with all rights reserved, unless otherwise indicated.

\title{
Pregnant driver injury investigations through modelling and simulation of full- frontal crashes with and without airbags
}

PLEASE CITE THE PUBLISHED VERSION

http://dx.doi.org/10.1504/IJHFMS.2011.041634

\section{PUBLISHER}

(C) Inderscience

\section{VERSION}

AM (Accepted Manuscript)

\section{PUBLISHER STATEMENT}

This work is made available according to the conditions of the Creative Commons Attribution-NonCommercialNoDerivatives 4.0 International (CC BY-NC-ND 4.0) licence. Full details of this licence are available at: https://creativecommons.org/licenses/by-nc-nd/4.0/

\section{LICENCE}

CC BY-NC-ND 4.0

\section{REPOSITORY RECORD}

Acar, B. Serpil, and Volkan Esat. 2019. "Pregnant Driver Injury Investigations Through Modelling and Simulation of Full-frontal Crashes with and Without Airbags". figshare. https://hdl.handle.net/2134/25638. 


\title{
Pregnant Driver Injury Investigations through Modelling and Simulation of Full-Frontal Crashes with and without Airbags
}

\author{
B. Serpil ACAR and Volkan ESAT, \\ Computer Science/Research School of Informatics, \\ Loughborough University, LE11 3TU, UK
}

\begin{abstract}
Road traffic accidents have become increasingly important element in maternal deaths. It is important to investigate the injury mechanisms and injury levels that pregnant women may be subjected to in order to improve transport safety.

The three dimensional computational model 'Expecting', which embodies a detailed multi-body model of a fetus in a finite element model of a uterus with a placenta, is developed at Loughborough University. The model is designed to simulate dynamic loading conditions that pregnant occupant may experience. In this study, 'Expecting' is used to study the kinematics of pregnant occupants to predict the injury levels to the pregnant driver in frontal crashes. The implications of 'No restraint', 'Seat Belt Only' and 'Seat Belt \& Airbag' cases are investigated for various crash severities, from 15 to 45 kph. Crash analysis injury criteria such as Head Injury Criterion (HIC), 3ms maximum, Combined Thoracic Index (CTI) and Viscous Criterion (Max VC) are used. The results suggest that the frontal airbag together with the correctly worn seatbelt provide better protection for the pregnant drivers.
\end{abstract}

\section{INTRODUCTION}

Pregnant women form a relatively vulnerable and sensitive group in road traffic accidents. Increasing attention is paid to pregnant women's involvement in automobile crashes in impact biomechanics. 6-7\% of all pregnancies are reported to be affected by trauma, around two-thirds of which are caused by motor-vehicle accidents (Pearlman, 1997). The most recent combined statistical data for the UK show that approximately 750,000 pregnant women each year are likely to be vehicle drivers or passengers during some or all stages of their pregnancy (NISRA, 2007; Office for National Statistics, 2007; The Scottish Government, 2008). One of the reasons for the increase in pregnant women involvement in automobile accidents is that more women are driving and driving longer distances than ever before (Haapaniemi, 1996). In the United States, from 1975 to 2001, the average number of annual vehicle miles driven by women of reproductive age has risen considerably due to various factors such as inadequate mass transportation systems, and increased employment of young women (Weiss, 2006). 
The correct seat belt position for pregnant women is defined as follows: 'the shoulder strap should be placed between the breasts and around the bump' while 'the lap strap should go across the hips, fitting comfortably under the bump', by the UK Department for Transport. Acar and Weekes reported that only $13 \%$ of pregnant women are wearing their seat belts correctly in accordance with the Department for Transport, which reveals that incorrect wearing of seat belts by pregnant women appears to be very critical (Acar and Weekes, 2004). Results from a survey in the USA show that prenatal counselling on seat belt use during pregnancy appears to be an important public health issue as many women do not regularly and correctly wear their seat belts (Sirin et al., 2007).

It is not possible to determine the safety of pregnant occupants and their risk of injury in automobile accidents by cadaver experiments and human volunteer tests due to ethical issues surrounding controlled laboratory experiments. Real world crash data is also limited. The Hybrid III small female ATD is integrated with a pregnancy insert in order to construct a physical pregnant woman dummy (Pearlman and Viano, 1996). The second generation pregnant ATD, 'MAMA2B' has a water filled bladder, equivalent to the size of a 30th week pregnant uterus, and a neoprene 'skin' jacket (Rupp et al., 2001). Neither a placenta nor a fetus is included in the model.

Computational human body models offer inexpensive and rapid test solutions with a greater level of anatomical detail, potentially yielding an improved biofidelic response over ATDs. The model of Moorcroft et al (2003), which integrates an FE uterus; into an existing $5^{\text {th }}$ percentile female occupant represents a woman at around the $30^{\text {th }}$ week of gestation in terms of abdominal size and shape. The model does not include a fetus. The model has been used to predict the risk of injury in various crash scenarios with a range of restraint set-ups.

This study reports the dynamic response of pregnant women during full-frontal accident simulations with 'Expecting'. The three dimensional computational model 'Expecting', which embodies a detailed multi-body model of a 38-week old fetus in a finite element model of a uterus with a placenta, has been developed by Acar and van Lopik at Loughborough University (Acar and van Lopik, 2009).

'Expecting' has already been used to investigate 'No Restraint', 'Seat Belt Only' and the 'Seat Belt \& Airbag' cases for fetus safety and 'No Restraint' case found to be unsafe for the fetus. In this study, the same groups of crash scenarios are used to predict the injury levels to the pregnant driver in frontal crashes.

The global kinematics of pregnant occupants, injury criteria such as HIC, 3ms maximum, CTI and Max VC are presented. This research investigates the general response of pregnant occupants in full-frontal accidents, particularly to demonstrate the injury levels that they are exposed to. 


\section{METHOD}

This study focuses on the well-being of pregnant women, and 'Expecting', the computational pregnant occupant model, is used to examine the kinematics of pregnant occupants to predict injury levels to the pregnant driver in frontal crashes. Expecting is developed at Loughborough University by Acar and van Lopik (2009) to investigate the dynamic responses of the pregnant driver and fetus during vehicle impacts as explained below.

\section{The Pregnant Occupant Model: 'Expecting'}

'Expecting', the computational pregnant occupant model, embodies the complexity of pregnant women's anatomy and anthropometric details based on measurements of over 100 pregnant women (Acar and Weekes, 2006; Acar, van Lopik, and Weekes, 2009). A detailed multi-body representation of a fetus within a finite element uterus model is also integrated into the model. The model is placed within a typical vehicle interior model, consisting of a seat, vehicle floor, pedals, bolsters and steering wheel as shown in Figure 1(a), in the multi-body/finite-element software package MADYMO (of TNO Automotive BV, Delft, The Netherlands) version 6.2 and then modified for version 6.4. The finite element uterus model is built in accordance with the fetus dimensions and configuration controlling the dimensions of the uterus to provide a snug fit around the fetus as shown in Figure 1(b). The multi-body fetus model is composed of 15 rigid bodies representing the various anatomical regions of the fetus interconnected by kinematic joints. A finite element layer of fat encloses the outer surface of the uterus. A total fetal mass is $3.3 \mathrm{~kg}$ and the resulting total mass of the uterus with the placenta and the fetus is nearly $4.60 \mathrm{~kg}$.

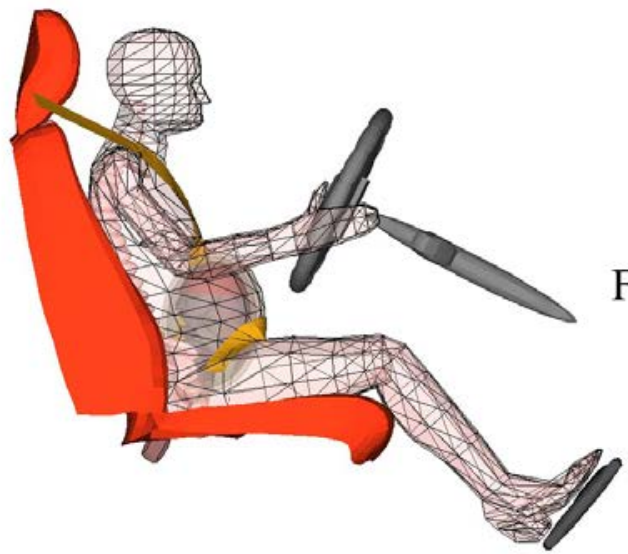

(a)

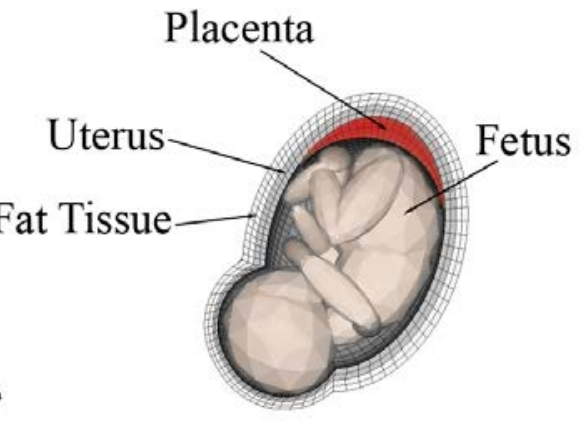

(b)

FIGURE 1. The pregnant occupant model 'Expecting' (a); uterus, placenta and fetus in 'Expecting' (b). 
The pregnant occupant model 'Expecting' has been validated against rigid-bar impact and belt loading tests performed by Hardy et al. (2001). Further details of the model can be found in (Acar and van Lopik, 2009). There is a lack of experimental data pertaining to the pregnant women and the fetus during car collisions, due to ethical considerations. Physical crash test with pregnant dummy results which investigates maternal injury criteria is not published either. Therefore, so far any computational pregnant model, with or without fetus, could not be validated against any experimental data. However the ability of 'Expecting' to predict fetal outcome results is also demonstrated by comparing the simulation results with directly comparable real life accident results and complete match is observed as explained in detail in Acar and Van Lopik, 2009.

\section{Simulation Parameters}

Full-frontal crash simulations are conducted to investigate the effects of seatbelt use and airbag deployment on the response of the pregnant occupant model 'Expecting' as the vehicle driver. The model incorporates a standard 3-point seat belt and an airbag. Finite Element driver airbag model with Computational Fluid Dynamics gas flow module exists in MADYMO (MADYMO Theory Manual, 2003). The driver airbag module incorporated into the system is a uniform pressure mode single chamber unit with gas jet effect. The airbag is folded and placed in a box at the centre of the steering wheel. The airbag inflator in the model supplies gas, mass and heat into the chamber. In 'Expecting', the airbag inflator is set to trigger at $15 \mathrm{~ms}$ following the onset of the impact.

Three groups of simulations are conducted. In the 'No Restraints', neither the 3-point seat belt is used nor the airbag is deployed; 'Seat Belt Only' group the seat belt is worn however the airbag is not deployed; whereas the 'Seat Belt \& Airbag' incorporates both the 3-point seatbelt and the airbag deployment. For each group, simulations are run with crash speeds of $15 \mathrm{kph}$ to $45 \mathrm{kph}$ with $5 \mathrm{kph}$ increments. Half-sine wave acceleration pulses with 120 ms duration are applied to the model (Figure 2).

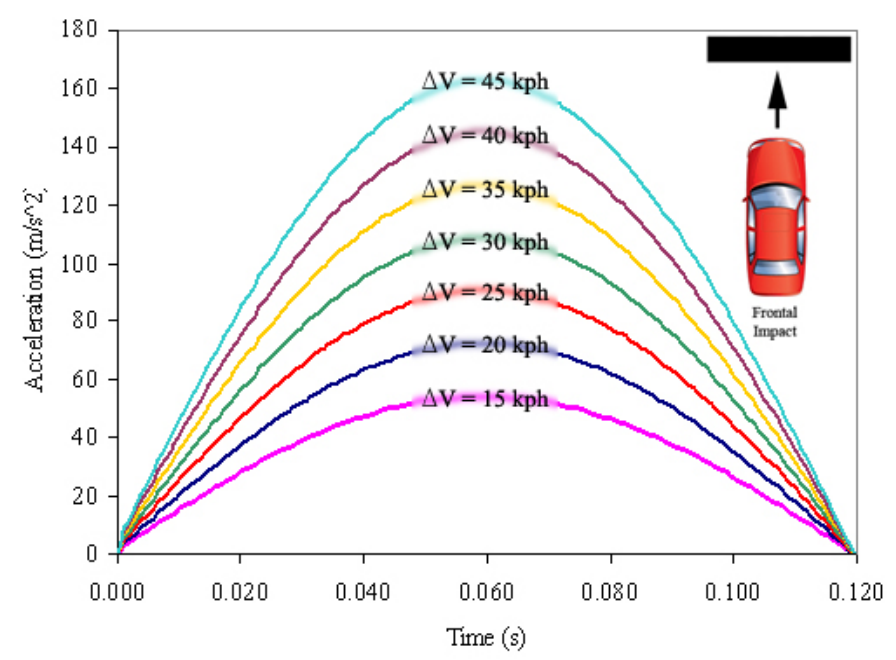

FIGURE 2. Half-sine acceleration pulses used as input for the crash simulations. 


\section{Injury Criteria}

In order to investigate the effects of the impact on pregnant women's head injury levels, HIC (Head Injury Criterion) values indicating the average value of acceleration over the most critical stage of deceleration are calculated. In this paper the notation HIC represents $\mathrm{HIC}_{36}$ where the critical stage range is taken as 36 milliseconds. $\mathrm{HIC}$ is based on the rate of change of kinetic energy and linear acceleration that the head and neck are subjected to. HIC is widely used in impact biomechanics and injury prevention and the critical HIC level for a $5^{\text {th }}$ percentile small female is proposed to be 1000 (Kleinberger, 1998).

The effects of the loads on pregnant women's thorax, created by the impact are found by using $3 \mathrm{~ms}$ maximum and CTI (Combined Thoracic Index). During a car impact, the thorax of the occupant is suddenly decelerated and the impact energy on the torso is predominantly absorbed by the thoracic deformations. $3 \mathrm{~ms}$ maximum criterion involves tracing the acceleration signal using a time window of 3 millisecond, where the highest acceleration level is the value for the criterion. Tolerance level of the $3 \mathrm{~ms}$ in frontal impact is usually accepted as $588 \mathrm{~m} / \mathrm{s}^{2}(60 \mathrm{~g})$ as a legislative performance limit (FMVSS Standard No. 208, 2006). CTI (Combined Thoracic Index) criterion is defined as a combination of spine acceleration and chest deflection ratios. It is widely accepted that CTI value less than or equal to 1, represents 25 percent probability of an AIS 3+ human chest injury (Kleinberger, 1998). Along with the $3 \mathrm{~ms}$ maximum and CTI calculations one other essential injury criterion is chosen to assess the effect of the impact over human injury tolerances. Viscous Criterion ( $\max V C$ ) provides a soft tissue injury assessment, which is compression and rate dependent. Max VC is defined as a measure of the energy dissipated by the viscous elements of the chest and max VC of $1.0 \mathrm{~m} / \mathrm{s}$ represents 25 percent probability of an AIS 3+ human chest injury (Lau and Viano, 1986).

\section{RESULTS}

This study concentrates on the well-being of pregnant women. In particular, widely used crash analysis criteria such as Head Injury Criterion (HIC), 3 ms maximum, Combined Thoracic Index (CTI) and Viscous Criterion (Max VC) values are calculated and compared for different severity crashes, 15-45 kph for 'No restraint', 'Seat Belt Only' and 'Seat Belt \& Airbag' cases. Figure 3 depicts the model in the $30 \mathrm{kph}$ frontal crash in all three cases. The results for these injury criteria for the pregnant driver in 'No restraint', 'Seat Belt Only' and 'Seat Belt \& Airbag' groups are given for 15-45 kph in Table 1 and in Figures 4-7.

Table 1 and Figure 4 demonstrate that HIC values become critical for pregnant women at speeds greater than $30 \mathrm{kph}$ crashes if no restraint system is used. Whereas with the seatbelt HIC values show a sharp increase and exceed the threshold of 1000 at around $44 \mathrm{kph}$. The sharp increase is due to the contact of pregnant driver's forehead with the steering wheel, whereas at speeds less than $30 \mathrm{kph}$, no contact between the head and 
the steering wheel is observed. This impact of the forehead onto the steering wheel becomes more severe with increasing crash speed, hence resulting in higher HIC values at higher crash speeds. Further simulations with 'Expecting' suggest that seatbelt and airbag collectively prevent head injuries for pregnant women as all HIC responses are far below the threshold value.

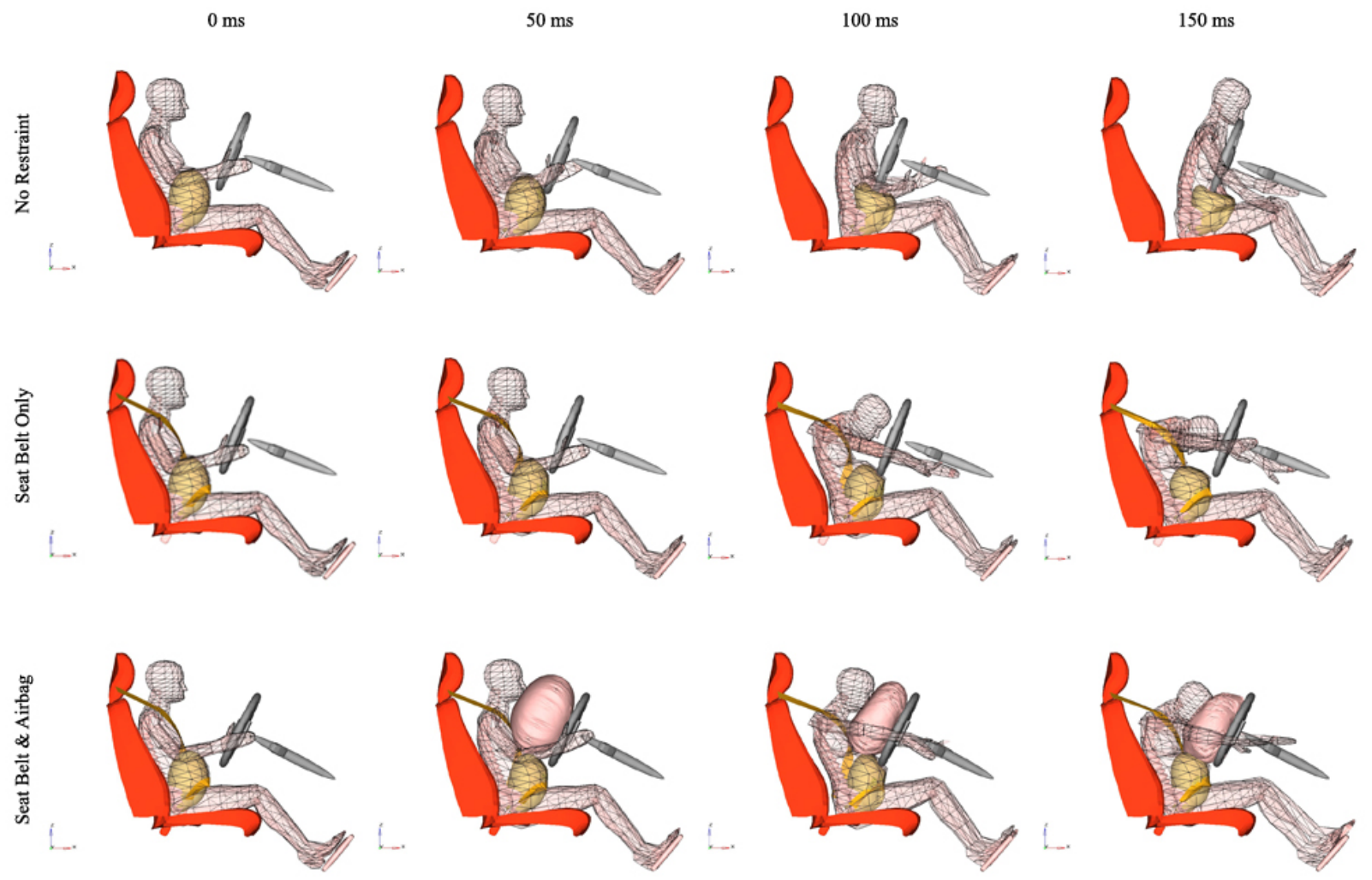

FIGURE 3. The model responses in the $30 \mathrm{kph}$ impact of all cases.

As for the $3 \mathrm{~ms}$ maximum, the values in Table 1 and Figure 5 indicate that the thorax injury is unavoidable if no restraint system is used. A comparison of the "Seat Belt Only" and "Seat Belt \& Airbag" cases shows that the 3ms values begin to separate for these crashes at speeds greater than $25 \mathrm{kph}$. Simulation outputs indicate that the airbag has a considerable cushioning effect on the thorax and therefore keeps the thorax linear acceleration levels down when compared to the "Seat Belt Only" case. At speeds less than $25 \mathrm{kph}$, 3ms values are very similar and far below the threshold value. $3 \mathrm{~ms}$ maximum values increase rapidly at speeds greater than $30 \mathrm{kph}$ for the 'Seat Belt Only' case and exceed the injury threshold of $588 \mathrm{~m} / \mathrm{s}^{2}$ at around $34 \mathrm{kph}$. This indicates a possible thorax injury without the airbag, whereas the values from the 'Seat Belt \& Airbag' case reach a reasonably low $308 \mathrm{~m} / \mathrm{s}^{2}$ at $45 \mathrm{kph}$.

Table 1 and Figure 6 show that CTI values in 'No Restraint' case reach the threshold of 1 in the interval 35-40 kph whereas all values for 'Seat Belt Only' case and the 'Seat Belt \& Airbag' case are considerably below the injury threshold value, increasing almost linearly with increasing speed, however far below the injury threshold even at $45 \mathrm{kph}$. 
The maximum VC values are shown in Table 1 and Figure 7. 'No Restraint' case reaches the threshold of 1 at 25-30 kph interval. All values for 'Seat Belt Only' case and the 'Seat Belt \& Airbag' case are below the injury threshold value, and increasing with the increasing speed, with seat belt only values being higher than seat belt and airbag values for crashes with greater than 35 kph speeds.

TABLE 1. HIC, 3ms Maximum, CTI and max VC values for the Pregnant Driver in 'No Restraint', 'Seat Belt Only' and 'Seat Belt \& Airbag' Groups

\begin{tabular}{|c|c|c|c|c|}
\hline & $\begin{array}{c}\text { Delta V } \\
\text { (kph) }\end{array}$ & No Restraint & Seat Belt Only & Seat Belt and Airbag \\
\hline \multirow{7}{*}{$\mathrm{HIC}$} & 15 & 177 & 9 & 2 \\
\hline & 20 & 373 & 19 & 5 \\
\hline & 25 & 646 & 35 & 11 \\
\hline & 30 & 972 & 77 & 21 \\
\hline & 35 & 1351 & 220 & 35 \\
\hline & 40 & 1752 & 625 & 53 \\
\hline & 45 & 2143 & 1131 & 78 \\
\hline \multirow{7}{*}{$\begin{array}{c}3 \mathrm{~ms} \\
\underset{\left(\mathrm{m} / \mathrm{s}^{2}\right)}{\operatorname{maximum}}\end{array}$} & 15 & 589 & 107 & 142 \\
\hline & 20 & 791 & 144 & 156 \\
\hline & 25 & 934 & 161 & 176 \\
\hline & 30 & 1121 & 304 & 207 \\
\hline & 35 & 1452 & 663 & 227 \\
\hline & 40 & 1724 & 1003 & 268 \\
\hline & 45 & 2106 & 1284 & 308 \\
\hline \multirow{7}{*}{ CTI } & 15 & 0.129 & 0.150 & 0.160 \\
\hline & 20 & 0.130 & 0.206 & 0.197 \\
\hline & 25 & 0.202 & 0.219 & 0.235 \\
\hline & 30 & 0.381 & 0.269 & 0.276 \\
\hline & 35 & 0.808 & 0.355 & 0.300 \\
\hline & 40 & 1.355 & 0.383 & 0.346 \\
\hline & 45 & 1.872 & 0.470 & 0.396 \\
\hline \multirow{7}{*}{$\begin{array}{c}\max V C \\
(\mathrm{~m} / \mathrm{s})\end{array}$} & 15 & 0.322 & 0.040 & 0.034 \\
\hline & 20 & 0.567 & 0.069 & 0.051 \\
\hline & 25 & 0.751 & 0.105 & 0.090 \\
\hline & 30 & 1.085 & 0.146 & 0.139 \\
\hline & 35 & 1.304 & 0.196 & 0.195 \\
\hline & 40 & 1.697 & 0.323 & 0.265 \\
\hline & 45 & 1.977 & 0.461 & 0.338 \\
\hline
\end{tabular}




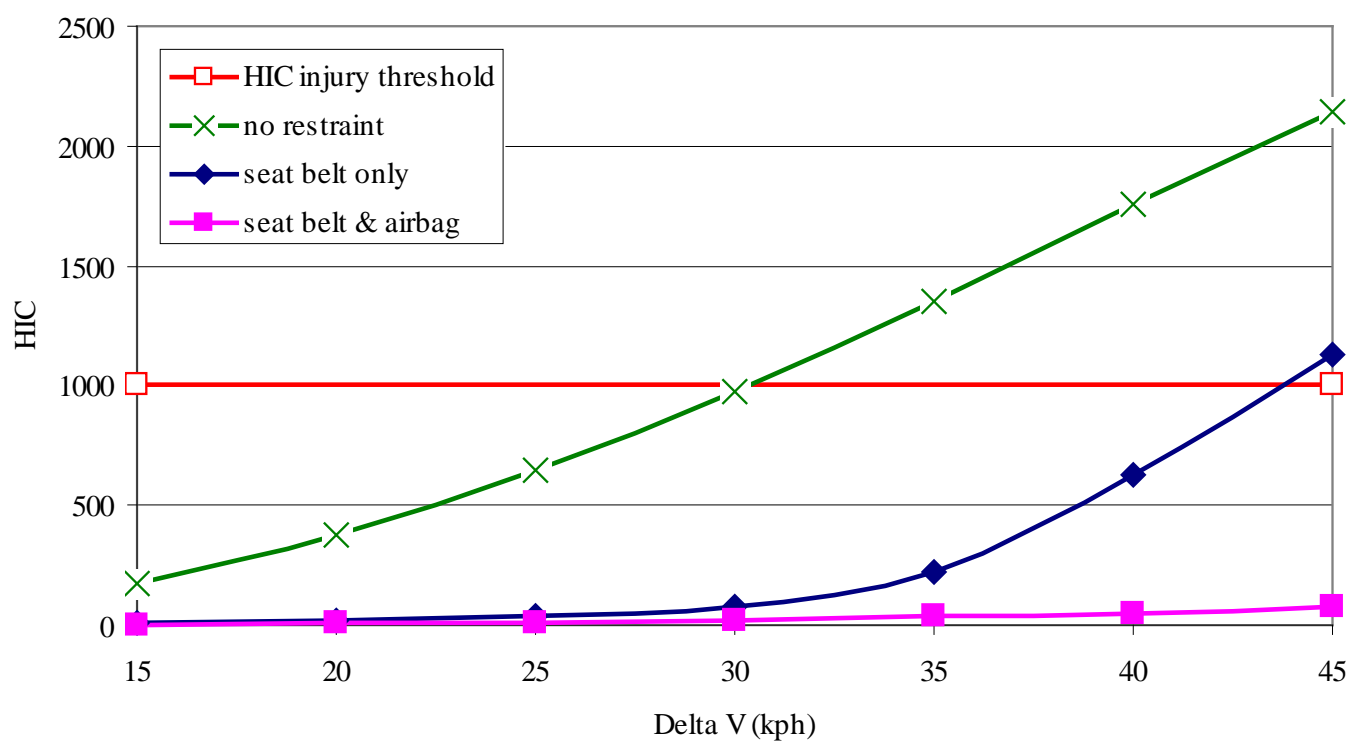

FIGURE 4. HIC injury comparison: 'No Restraint', 'Seat Belt Only' and 'Seat Belt \& Airbag'.

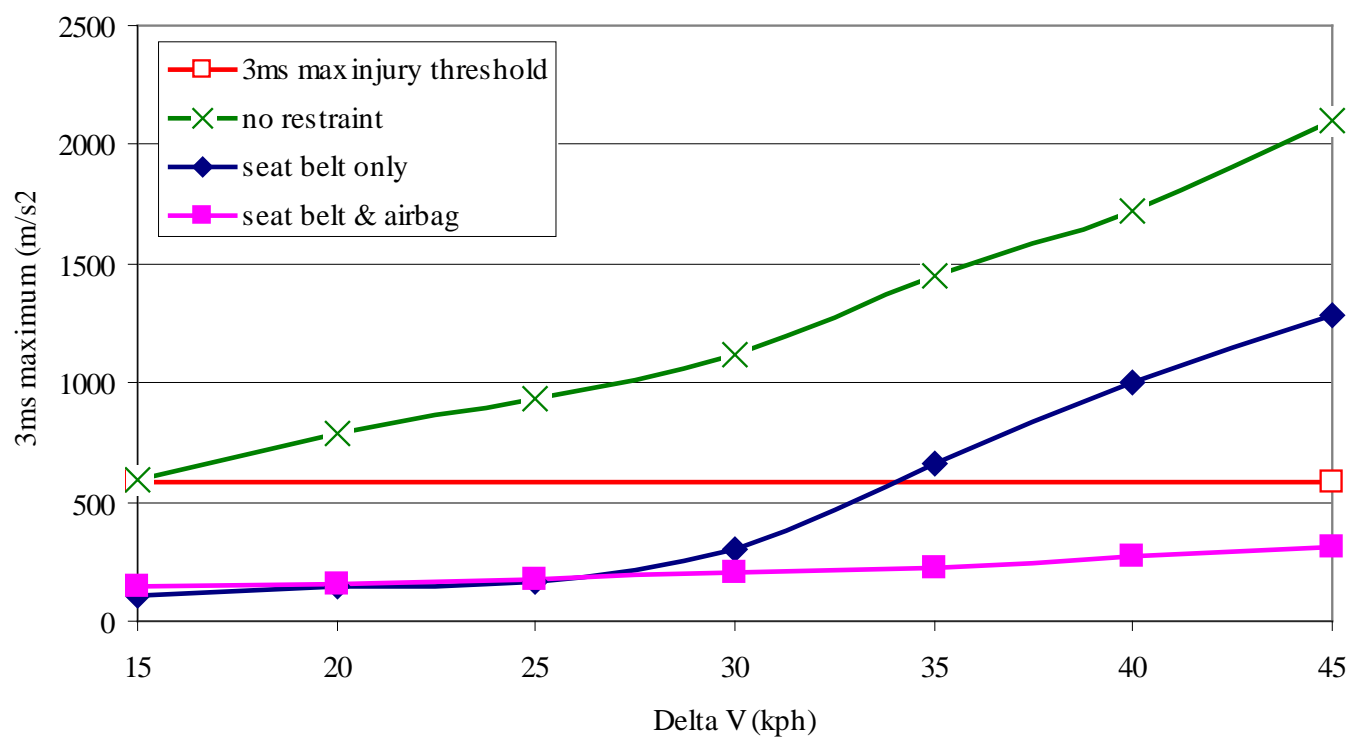

FIGURE 5. 3ms maximum injury comparison: 'No Restraint', 'Seat Belt Only' and 'Seat Belt \& Airbag'. 


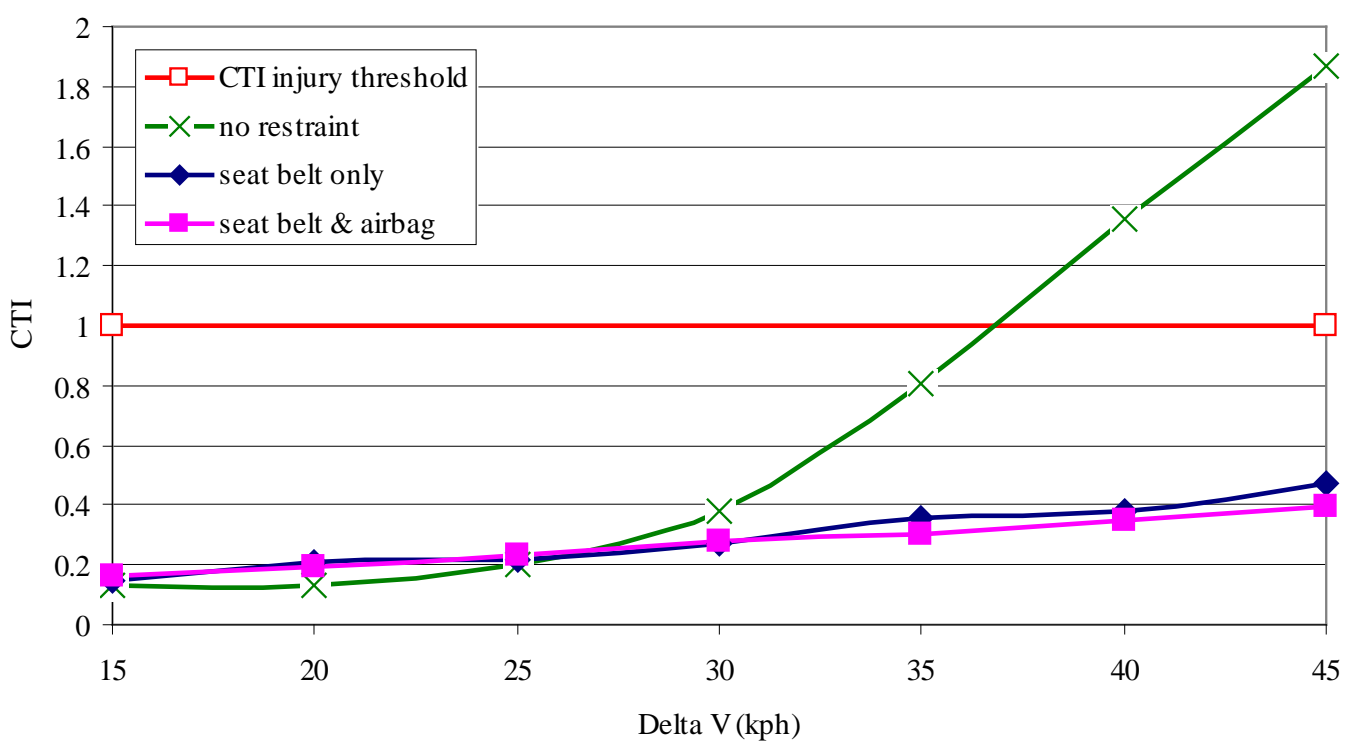

FIGURE 6. CTI injury comparison: 'No Restraint', 'Seat Belt Only' and 'Seat Belt \& Airbag'.

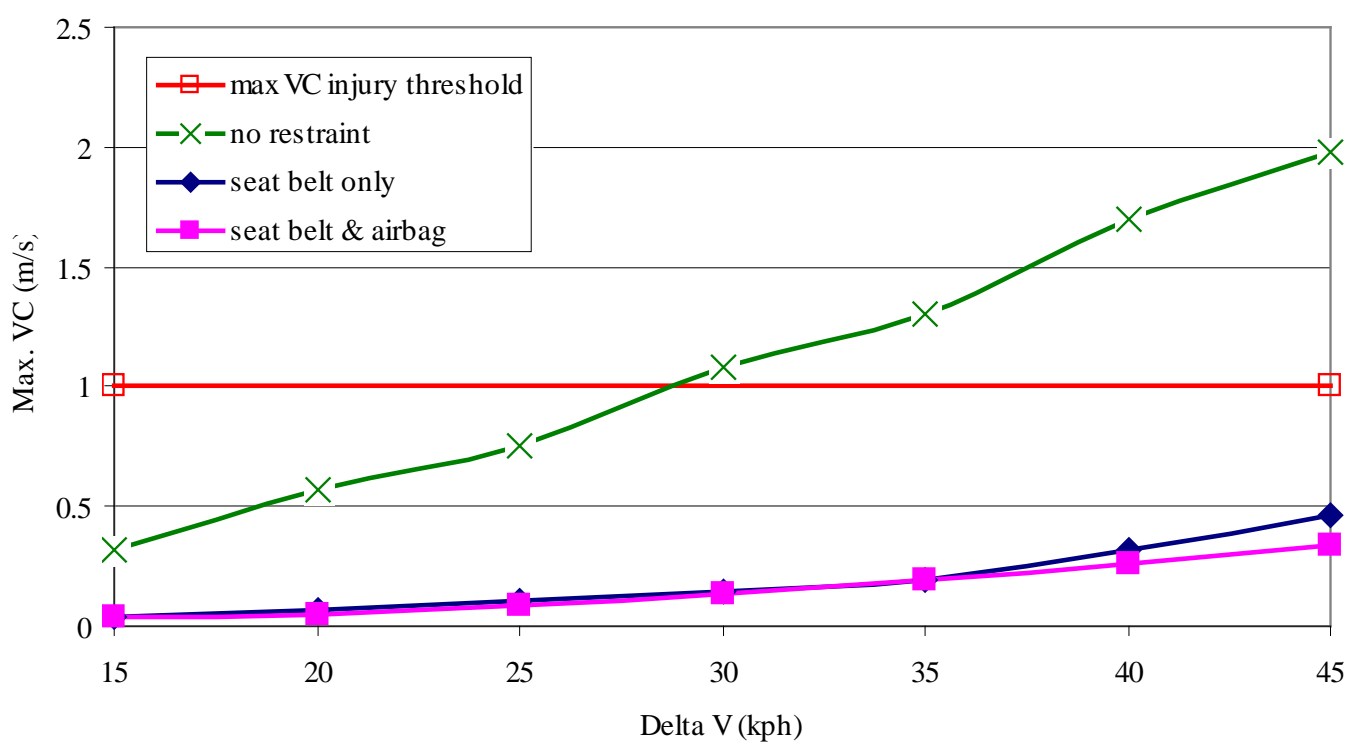

FIGURE 7. Maximum VC injury comparison: 'No Restraint', 'Seat Belt Only' and 'Seat Belt \& Airbag'. 


\section{DISCUSSION AND CONCLUSIONS}

In earlier studies 'Expecting' is used to investigate the crash and restraint conditions under which placental abruption might occur. For example, maximum strain in the uterus at the placental location, maximum abdominal deformations due to lap portion of the 3-point seatbelt and the steering wheel loadings are presented and compared for 'No Restraint', 'Seat Belt Only' and 'Seat Belt \& Airbag' in (Acar and van Lopik, 2009). These investigations are related to the livelihood of the fetus.

In this paper, 'Expecting' is used to study the kinematics of pregnant occupants to predict injury levels to the pregnant driver herself in frontal crashes. The authors acknowledge that every pregnancy could present a different case. Conditions of the vehicles, type of the driver airbag module and the circumstances surrounding the accidents could also vary a great deal and hence could give a range of results. This research, without loss of generalisation, assumes the conditions explained in the Methods section and compares the restraint conditions to find out the best settings for pregnant women's safety.

This research focuses on three main groups of simulations with 'Expecting' to investigate the difference between seat belt use and the airbag deployment on the response of the pregnant driver to full-frontal impacts. The whole experiment is repeated for seven crash speeds. Within each group, the simulations are conducted under identical conditions and only the speed variable is changed. In the 'No Restraint' group simulations, there is neither a seatbelt nor an airbag in the car. The 'Seat Belt Only' group include a 3-point seat belt however does not include an airbag in the system in order to demonstrate the possible effects of a lack of airbag or airbag deployment within the vehicle when only the seat belt is worn, whereas 'Seat Belt \& Airbag' group incorporates the airbag deployment.

Results within the three groups of simulations reveal that for pregnant women the risk of head injuries and thorax injuries increases with crash speed independent of the injury criteria used. Furthermore, the 'No Restraint' group simulations reveal that according to 3 ms maximum injury criterion, thorax injuries are unavoidable at any crash severity if restraint systems are not used. Other injury criteria considered in this article reveal that 27-37 kph seems to be the critical interval where injuries start to become inevitable without any restraint system.

Wearing the seat belt seems to reduce the risk of head injuries for lower than $45 \mathrm{kph}$ crashes. It also reduces the risk of thorax injuries, and the results are far below the threshold at all crashes up to $45 \mathrm{kph}$ if $\mathrm{CTI}$ and maximum VC criteria are used whereas $3 \mathrm{~ms}$ maximum injury values suggest that the seatbelt wearing alone is not possible to avoid thorax injuries if the crash speed is over $34 \mathrm{kph}$.

There are no physical crash test results with MAMA2B to investigate $\mathrm{HIC}, 3 \mathrm{~ms}$ maximum, CTI and max VC in the literature. In (Moorcroft et al., 2004), a 30-week pregnant computational model is used to simulate a $35 \mathrm{kph}$ frontal crash. They found 
that the pregnant driver's VC value is 0.72 (below the threshold value of 1.0) and HIC value 156 (Far below the threshold value of 1000) suggesting 'no injury' according to these criteria in the 'None' (equivalent of 'No Restraint') case. Our corresponding results for the VC and HIC values are 1.304 and 1351 (both above the threshold values) suggesting injuries to the pregnant driver. Further VC and HIC results for different speeds with the 30-week pregnant model in (Duma et al., 2005) suggest no injuries whatsoever to the pregnant driver herself even in 'None' cases. Our results in this paper are based on experiments with the more advanced pregnant driver model 'Expecting' and consistently suggest more injury risks for the 'No Restraint' case than other cases.

This disagreement with the studies with an earlier model is not surprising since 'Expecting' is based on anthropometric data that represents the pregnant women and the fetus. It is essential to include an anthropometrically correct fetus into the uterus to create a more realistic pregnant driver model. Fetus' inclusion within the uterus would arguably create a more realistic dynamic simulation of the model's response, and fetus' realistic anatomical features and joint properties are observed to have significant effects on the kinetics and the kinematics of the pregnant woman during impacts. Hence it is reasonable to expect more biofidelic results from a model which much more closely represents a pregnant woman including a representative fetus.

Simulations of full frontal crashes up to $45 \mathrm{kph}$ speed difference with the 38-week pregnant model 'Expecting' suggest that both head and neck injuries and thorax injuries can be avoided by pregnant women by wearing the seat belt correctly in accordance with the UK Department for Transport of UK and NHTSA of USA guidelines and having the airbag deployed.

Earlier research with 'Expecting' suggested that in frontal crashes up to $45 \mathrm{kph}$ speed difference, the correctly worn seatbelt and airbag provide better protection to the fetus. This research suggests that they also provide better protection to pregnant women themselves.

\section{ACKNOWLEDGEMENTS}

The authors thank EPSRC (Engineering and Physical Research Council, UK) and IMCRC, Loughborough University (Innovative Manufacturing and Construction Research Centre) for funding the research projects. The authors also thank Advanced Simtech for its reduced academic licence fees for MADYMO.

\section{REFERENCES}

Acar, B.S. and van Lopik, D. (2009) 'Computational pregnant occupant model, 'Expecting', for crash simulations', Proc. IMechE Part D: J. Automobile Engineering, Vol. 223, pp.891-902.

Acar, B.S. and Weekes, A.M. (2004) 'Designing for safety during pregnancy through a system for automotive engineers', International Journal of Crashworthiness, Vol. 9, No. 6, pp.625-631. 
Acar, B.S. and Weekes, A.M. (2006) 'Measurements for Pregnant Occupant Safety', International Journal of Vehicle Design, Vol. 42, No. 1-2, pp.101-118.

Acar, B.S., van Lopik, D. and Weekes, A.M. (2009) "Expecting': Occupant Model Incorporating Anthropometric Details of Pregnant Women', International Journal of Vehicle Design, Vol. 51, No. 3-4, pp.374-385.

Duma, S., Moorcroft, D., Stitzel, J. and Duma, G. (2005) 'A Computational Model of the Pregnant Occupant: Effects of Restraint Usage and Occupant Position on Fetal Injury Risk'. Paper presented at the 19th International Technical Conference on the Enhanced Safety of Vehicles. Paper Number 05-0367-O. June 6-9, 2005. Washington D.C., USA.

FMVSS Standard No. 208 (2006) Occupant crash protection, NHTSA.

Haapaniemi, P. (1996) 'Women's highway deaths on the rise', Traffic Safety, Vol. 96, pp.6-11.

Hardy, W.N., Schneider, L.W. and Rouhana, S.W. (2001) "Abdominal impact response to rigid-bar, seatbelt, and airbag loading", Stapp Car Crash J., Vol. 45, pp. 1-32.

Kleinberger, M., Sun, E., Eppinger, R., Kuppa, S. and Saul, R. (1998) Development of improved injury criteria for the assessment of advanced automotive restraint systems, NHTSA report.

Lau, I.V. and Viano, D.C. (1986) 'The viscous criterion - A new index of injury induced by high speed impact', Journal of Biomechanics, Vol. 19, No. 6, p.485.

MADYMO Theory Manual (2003) Airbag Models, (pp.253-296), TNO MADYMO BV.

Moorcroft, D., Duma, S., Stitzel, J. and Duma, G. (2003) 'A finite element and multi-body model of the pregnant female occupant for the analysis of restraint effectiveness', SAE Transactions, 2003-010157, Vol. 112, No. 6, pp.62-70.

Moorcroft, D., Stitzel, J., Duma, S. and Duma G. (2004) 'The Effect of Pregnant Occupant Position and Belt Placement on the Risk of Fetal Injury'. Paper presented at the 2004 SAE World Congress. March 8-11, 2004. Detroit, Michigan, USA.

NISRA (2007). Statistics Press Notice - Births in Northern Ireland.

Office for National Statistics (2007). Birth Statistics - Review of the Registrar General on births and patterns of family building in England and Wales. Series FM1, No. 35.

Pearlman, M.D. (1997) 'Motor vehicle crashes, pregnancy loss, and preterm labor', International Journal of Gynaecology \& Obstetrics, Vol. 57, No. 2, pp.127-132.

Pearlman, M.D. and Viano, D. (1996) 'Automobile crash simulation with the first pregnant crash test dummy', Am J Obstet Gynec, Vol. 175, pp.977-981.

Rupp, J.D., Klinich K.D., Moss, S., Zhou, L., Pearlman, M.D. and Schneider L.W. (2001) 'Development and testing of a prototype pregnant abdomen for the small female Hybrid III small female ATD', Stapp Car Crash Journal, Vol. 45, pp.61-78.

Sirin, H., Weiss, H.B. and Sauber-Schatz, E.K. (2007) 'Seat belt use, counselling and motor-vehicle injury during pregnancy: results from a multi-state population based survey', Maternal and Child Health Journal, Vol. 11, pp.505-510.

The Scottish Government (2008). Births in Scotland - High Level Summary of Statistics Trend. GROS Registration Data, Statistics. Obtained through the internet: http://www.scotland.gov.uk/Topics/Statistics/Browse/Population-Migration/TrendBirths, [accessed 17/4/2008].

Weiss, H.B. (2006) 'Hidden epidemic of maternal, fetal, and neonatal mortality and injury from crashes A case of societal neglect?' Transportation Research Record: Journal of the Transportation Research Board, No. 1956, pp.133-140. 